Article

\title{
Concurrent Metabolic Profiling and Quantification of Aromatic Amino Acids and Phytohormones in Solanum lycopersicum Plants Responding to Phytophthora capsici
}

\author{
Msizi I. Mhlongo ${ }^{1}$, Lizelle A. Piater ${ }^{1}$ (D), Paul A. Steenkamp ${ }^{1}\left(\mathbb{D}\right.$, Nico Labuschagne ${ }^{2}$ \\ and Ian A. Dubery ${ }^{1, * \mathbb{D}}$ \\ 1 Department of Biochemistry, University of Johannesburg, P.O. Box 524, Auckland Park, \\ Johannesburg 2006, South Africa; mmhlongo@uj.ac.za (M.I.M.); lpiater@uj.ac.za (L.A.P.); \\ psteenkamp@uj.ac.za (P.A.S.) \\ 2 Department of Plant and Soil Sciences, University of Pretoria, Private Bag X20, Hatfield, \\ Pretoria 0028, South Africa; nico.labuschagne@up.ac.za \\ * Correspondence: idubery@uj.ac.za; Tel.: +27-11-559-2401
}

Received: 9 October 2020; Accepted: 12 November 2020; Published: 16 November 2020 updates

\begin{abstract}
Pathogenic microorganisms account for large production losses in the agricultural sector. Phytophthora capsici is an oomycete that causes blight and fruit rot in important crops, especially those in the Solanaceae family. P. capsici infection is difficult to control due to genetic diversity, arising from sexual reproduction, and resistant spores that remain dormant in soil. In this study, the metabolomics of tomato plants responding to infection by P. capsici were investigated. Non-targeted metabolomics, based on liquid chromatography coupled to mass spectrometry (LC-MS), were used with multivariate data analyses to investigate time-dependent metabolic reprogramming in the roots, stems, and leaves of stem-infected plants, over an 8 day period. In addition, phytohormones and amino acids were determined using quantitative LC-MS. Methyl salicylate and 1-aminocyclopropane-1-carboxylate were detected as major signalling molecules in the defensive response to P. capsici. As aromatic amino acid precursors of secondary metabolic pathways, both phenylalanine and tryptophan showed a continuous increase over time in all tissues, whereas tyrosine peaked at day 4. Non-targeted metabolomic analysis revealed phenylpropanoids, benzoic acids, glycoalkaloids, flavonoids, amino acids, organic acids, and fatty acids as the major classes of reprogrammed metabolites. Correlation analysis showed that metabolites derived from the same pathway, or synthesised by different pathways, could either have a positive or negative correlation. Furthermore, roots, stems, and leaves showed contrasting time-dependent metabolic reprogramming, possibly related to the biotrophic vs. necrotrophic life-stages of the pathogen, and overlapping biotic and abiotic stress signaling. As such, the targeted and untargeted approaches complemented each other, to provide a detailed view of key time-dependent metabolic changes, occurring in both the asymptomatic and symptomatic stages of infection.
\end{abstract}

Keywords: aromatic amino acids; correlation; metabolomics; Phytophthora capsici; phytohormones; tomato; time-dependent metabolic reprogramming

\section{Introduction}

Phytophthora capsici is an oomycete pathogen with a broad host range, and regarded as one of the 10 most important plant pathogens. P. capsici infects more than 45 plant species (e.g., cucurbits, pepper, eggplant, and tomato, etc.), causing damage (crow-, root-, and fruit-rot) to many economically 
important crops. In this regard, disease occurrence and severity has escalated in recent years, leading to economic losses worldwide. P. capsici is a hemibiotrophic pathogen, with an initial biotrophic phase followed by a switch to a necrotrophic lifestyle. Depending on environmental conditions, infection of tomato plants can occur via the roots, crown and foliage, or even the fruit [1-3].

In general, plants are continuously exposed to attack by pathogenic microorganisms, both above and below ground. In defence, multi-layered mechanisms consisting of constitutive and inducible responses are employed [4,5]. The initial stages of a plant-pathogen interaction include the perception of microbe/pathogen-associated molecular patterns (M/PAMPs) or damage-associated molecular patterns (DAMPs) by specialised pattern recognition receptors (PRRs) [6-8], activation of intracellular signalling (mostly the mitogen-activated protein kinase (MAPK) pathway), generation of reactive oxygen species (ROS), and production of defence-associated phytohormones [9-12]. The latter play a pivotal role in plant biochemical processes, including defence responses $[4,13,14]$, and accumulate in varying amounts in response to attempted infection or insect attacks, thereby leading to reprogramming of the transcriptome, activation of defence genes, and production of phytoalexins $[4,15,16]$. To minimise the fitness costs of unnecessary activation of defence genes, and to launch a specific immune response, plants produce a mixture of hormones that are specific to the stress detected. Salicylic acid (SA)-induced resistance is more effective against biotrophic pathogens [17], while jasmonic acid (JA)- and/or ethylene (ET)-induced resistance is operative against necrotrophic pathogens and herbivore attack. Different plant species can employ different signal transduction pathways to specify the immune response. Other phytohormones, including cytokinins, auxins, abscisic acid (ABA), gibberellins, and brassinosteroids, have been reported to play a role in plant resistance; however, knowledge regarding the significance of these molecules is limited $[4,14,18,19]$. These hormones interact either antagonistically or synergistically with the SA-JA-ET signalling backbone, and reprogram the defence output [19-21].

Following perception and signalling, plants modify their cell walls through lignin synthesis and callose deposition, as well as the biosynthesis of antimicrobial phytoalexins [4,22,23]. The ability of plants to mount an immune response under stress conditions is associated with a high probability of survival under such conditions. However, these responses are energy demanding and have high fitness costs. For plant defence execution, energy is critical, and plays an important role in defence gene expression in support of various metabolic pathways [24]. Thus in the past, attempts have been made to understand the underlying metabolic pathways involved in plant physiological processes (energy regulation, growth and development of tissue, and reproduction) and defence response regulation [25]. Amino acids are molecules used as sources of carbon and nitrogen, and are precursors of the molecular skeletons of compounds to be synthesised. Upon infection, synthesis of these metabolites can be supported by energy-generating pathways such as the tricarboxylic acid (TCA) pathway, glycolysis, and the pentose phosphate pathway $[25,26]$, which then drives immune defence responses. The 20 amino acids can be converted by various enzymatic reactions to seven precursors and intermediates ( $\alpha$-ketoglutarate, acetoacetate, acetyl-CoA, fumarate, oxaloacetate, pyruvate, and succinyl-CoA) for energy generation [27]. In turn, the aromatic amino acids (Phe and Tyr) provide the phenolic group for the production of various phenolic molecules via the phenylpropanoid pathway, and these molecules have direct and indirect effects on pathogens [28-31]. Aromatic amino acids (Trp and Tyr) can also be converted to various amines such as serotonin and tyramine [32]. Trp also serves as a precursor for the production of indole-3-acetic acid, a phytohormone playing a pivotal role in plant growth and resistance [33,34].

Under stressed conditions plants are known to sacrifice some energy required for physiological processes, which is then channelled towards defence activation [27,35], and is associated with primary metabolite modification. Using metabolomics, one can obtain a "snapshot-in-time" of these events, and to deduce metabolic reprogramming taking place during plant defence responses. By definition, this omics approach is an unbiased analysis of the whole metabolome in a living system [36]. However, chemical diversity of metabolites is a major challenge, making whole metabolome analysis difficult $[36,37]$. Depending on the chosen analytical platform, the extraction method will favour certain metabolites in the said scenario. 
P. capsici is a broad-host-range pathogen, and disease initiation and progression will depend on the site of infection, the initial inoculum, the physiological condition of the plants, and the inherent ability of the cultivar to withstand the infection/counter the actions of the pathogen [1-3]. Previous studies have investigated plant defences to $P$. capsici, with no/very few metabolic studies that included looking at the metabolic reconfiguration correlated to the defensive state of the plant to the pathogen. Thus, in the present study, both non-targeted and targeted analyses were used to investigate the time-dependent metabolic reprogramming in tomato plants responding to P. capsici infection.

\section{Results}

\subsection{Symptom Development}

At the outset, we monitored the symptom progression in the tomato plants (S. lycopersicum "Moneymaker") inoculated with P. capsici spores in time-course experiments (Figure S1). As observed in previous studies [38], disease symptoms were observed 4 to $8 \mathrm{~d}$ post-inoculation (d.p.i.), with day 8 showing a complete diseased state. Symptoms included wilting and crown rot, and, in some instances, the lower stem collapsed (stem rot due to stem inoculation), leading to rapid wilting of the canopy and plant death (Figure S2). Phytophthora spp. are destructive pathogens with a hemi-biotrophic lifestyle (this features a biotrophic phase which then switches to a necrotropic phase) [39]. Thus, P. capsici infection involves a biotrophic phase in which the host plant appears healthy and unharmed, lasting for $0-2 \mathrm{~d}$ (Figure S1). Following successful infection, the pathogen switches to the necrotrophic phase (4-8 d), accompanied by wilting and subsequent plant collapse (Figure S1).

\subsection{Aromatic Amino Acid Quantification}

In order to investigate the involvement of aromatic amino acids (Phe, Trp, and Tyr) in the tomato plant response to $P$. capsici inoculation, 50\% methanol extracts of roots, stems, and leaves were analysed using an multiple reaction monitoring (MRM) method, based on ultra-high-performance liquid chromatography triple quadrupole mass spectrometry (UHPLC-QqQ-MS). The content of Phe (Figure 1A) was found to be differentially modulated by P. capsici inoculation, where significantly increased accumulation in stems $(1.8-8 \mu \mathrm{g} / \mathrm{g})$ and leaves $(3.8-17 \mu \mathrm{g} / \mathrm{g})$ from 2 to 8 d.p.i. were found, while a decrease $(1.5-0.4 \mu \mathrm{g} / \mathrm{g})$ over the same time period was observed in the roots when compared to non-treated (NT) plants. The Trp (Figure 1B) content followed the same trend as Phe (accumulation from day 2 to 8 ) in both stems and leaves of infected plants, with a range increase of 1.3-2.5 $\mu \mathrm{g} / \mathrm{g}$ and $2.5-5.5 \mu \mathrm{g} / \mathrm{g}$, respectively. However, the content in roots increased from 1.3-3.2 $\mu \mathrm{g} / \mu \mathrm{g}$ between day 2 and 4 post-inoculation, and then decreased to $\sim 1.3 \mu \mathrm{g} / \mathrm{g}$ thereafter (day 6 and 8) (Figure 1B). Lastly, the quantities of Tyr increased in both stems and leaves (similar trend to Phe and Trp) (Figure 1C), from $0.1-1.8 \mu \mathrm{g} / \mathrm{g}$ and $1.5-3.8 \mu \mathrm{g} / \mathrm{g}$, from 2 to 8 d.p.i., respectively. However, in leaves, a slight decrease from 3.8-3.0 $\mu \mathrm{g} / \mathrm{g}$ was observed on day 8 (Figure 1C). In roots, the Tyr content in P. capsici-treated plants increased from days 2 to 4 , followed by a slight decrease on days 6 to 8 , but remained significantly higher than that of the NT plants (Figure 1C).

\subsection{Quantification of Methyl Salicylic Acid and 1-Aminocyclopropane-1-Carboxylic Acid}

Six phytohormones (SA and methyl salicylate, MeSA; indole acetic acid, IAA; ABA; JA, and methyl jasmonate, MeJA) as well as the ET precursor, 1-aminocyclopropane-1-carboxylic acid (ACC), were targeted for quantification. However, only two (MeSA and ACC) are presented here, as they showed differential regulation during pathogen progression, and were found to be above the LOQ for the different time points. In root tissues, the MeSA content significantly decreased with time, followed by a sharp increase on day 8 (PC day 8) (Figure 2A). In stem tissue, the MeSA content was significantly higher than both controls on days 2 and 8, whereas at day 4 a significant difference was observed between NT day 2 and PC day 4 plants. On day 6 no significant difference was observed when compared to both controls (NT day 2 and NT day 8) (Figure 2A). The ACC content showed increased 
accumulation in roots from day 2 to day 4 post-infection, after which a decrease was observed; however, it remained significantly higher than the NT plants over time (Figure 2B). In stems, significantly higher contents of ACC were observed from 4 to 8 d.p.i. (Figure 2B). A similar trend was observed in leaves where the ACC content was significantly higher from 4 to 8 d.p.i. (Figure 2B).

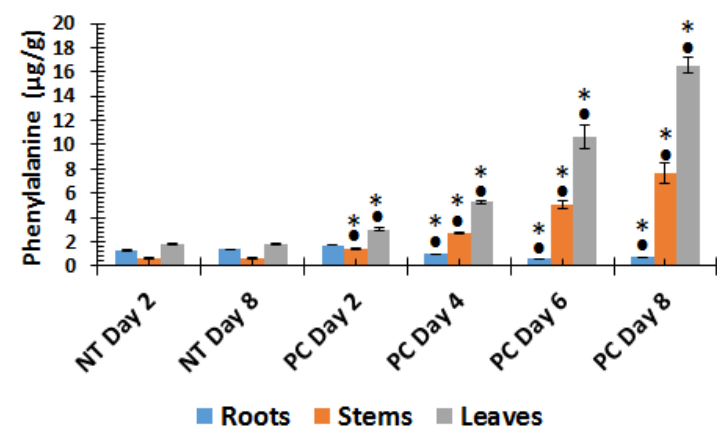

C

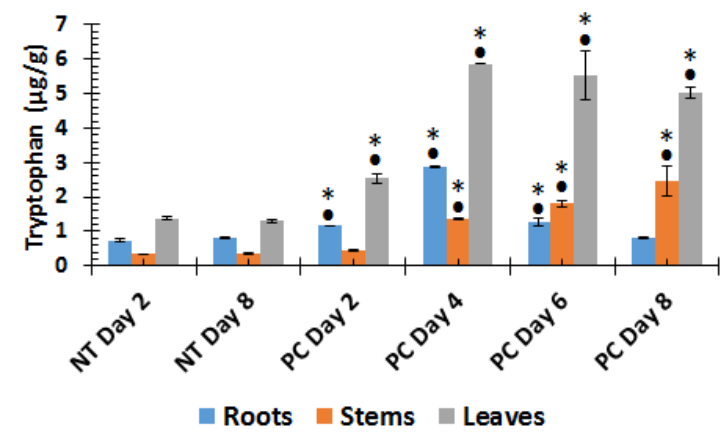

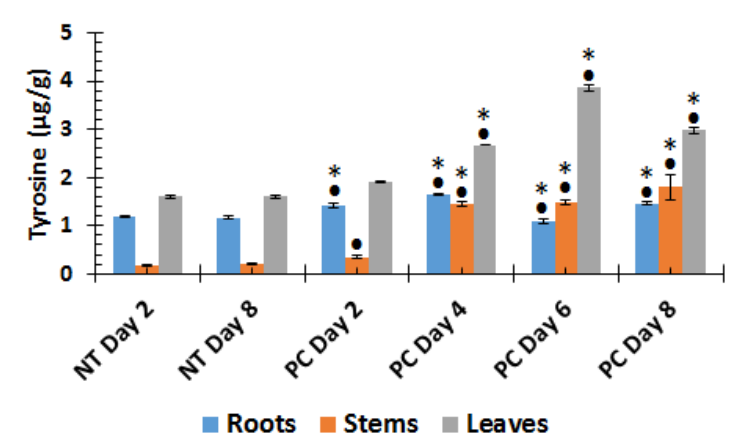

Figure 1. Changes in aromatic amino acid content in tomato plant tissue harvested at different time points following Phytophthora capsici (PC) inoculation in stems vs. non-treated (NT) plants. (A): Phenylalanine, (B): Tryptophan, (C): Tyrosine. Upon harvesting, the plants were divided into root, stem, and leaf tissue. Values are means $\pm \mathrm{SD}(n=3$ independent sampling). Extracts were prepared from $200 \mathrm{mg}$ of pulverised tissue, and all concentrations are expressed as $\mu \mathrm{g} / \mathrm{g}$ fresh weight (FW). An asterisk $(*)$ or a $\operatorname{dot}(\bullet)$ indicates the statistical significance with a $p$-value $<0.05$ compared with the non-treated plants, with $\bullet$ indicating a comparison between NT day 2 and the PC infection on days 2-8 post-infection, and * a comparison between NT day 8 and the PC infection on days 2-8 post-infection. The results show a time-dependent differential reprogramming of aromatic amino acids levels in the various tissues.

A

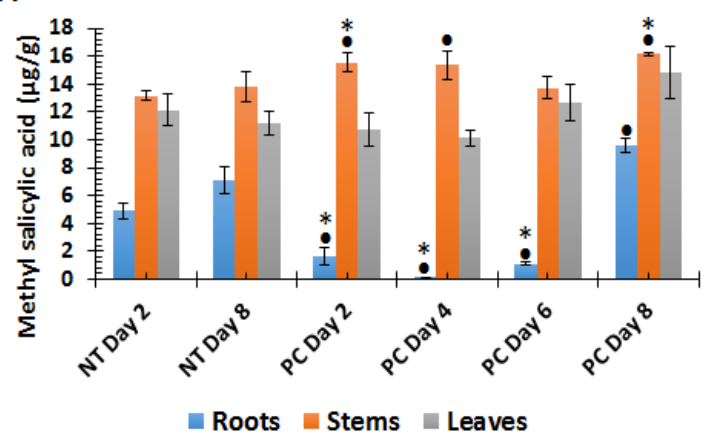

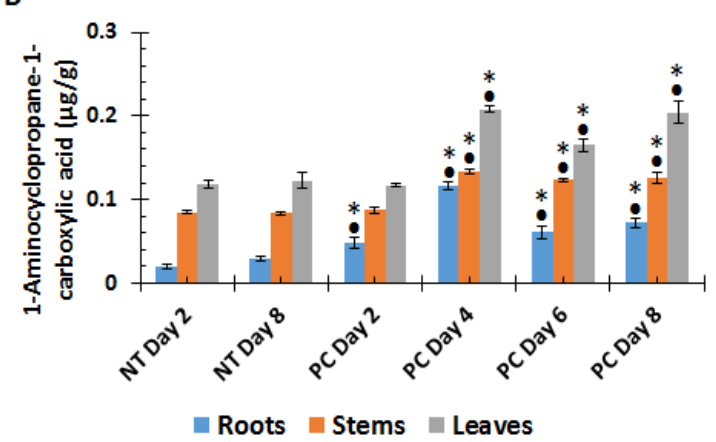

Figure 2. Changes in phytohormone levels in tomato plant tissues harvested at different time points following P. capsici (PC) inoculation in stems vs. non-treated (NT) plants. (A): Methyl salicylic acid and (B): 1-Aminocyclopropane-1-carboxylic acid. Extracts were prepared from $200 \mathrm{mg}$ of pulverised tissue, and all concentrations are expressed as $\mu \mathrm{g} / \mathrm{g}$ fresh weight $(\mathrm{FW})$. An asterisk ${ }^{*}$ ) or a $\operatorname{dot}(\bullet)$ indicates the 
statistical significance with a $p$-value $<0.05$ compared with the non-treated plants, with $\bullet$ indicating a comparison between NT day 2 and the PC infection on days 2-8 post-infection, and * a comparison between NT day 8 and the PC infection on days 2-8 post-infection. The results show a time-dependent differential reprogramming of MeSA and ACC in the various tissues.

\subsection{Metabolic Profiling of P. capsici-Induced Changes in Tomato Plants}

\subsubsection{Multivariate Data Analysis}

Various studies have shown that plant-pathogen interactions lead to the activation of different metabolic pathways and the concomitant accumulation of defence metabolites. In order to gather such metabolic information, a non-targeted approach was used to analyse the methanol extracts of non-treated (NT) and P. capsici (PC)-infected tomato plants with the aid of ultra-high-performance liquid chromatography, quadrupole time-of-flight mass spectrometry (UHPLC-qTOF-MS) analysis. Plant samples are known to contain thousands of highly diverse molecules (both chemically and structurally diverse); as such it is important to first resolve the sample constituents by chromatographic separation, followed by electrospray ionisation (ESI)-MS to detect the eluents. Base peak intensity (BPI) chromatograms (Figures S3-S5) of the tomato plant extracts following treatment with P. capsici showed some variation in peak intensities, accumulation of new peaks, and disappearance of some peaks. This is an indication that $P$. capsici altered cellular metabolism, resulting in time-dependent metabolic changes.

Metabolomic analyses generate huge data sets that are difficult to visually explore, and it is difficult to explain all differences observed in an MS chromatogram. As such, statistical analyses are used to mine the collected multidimensional data, and to pinpoint signatory biomarkers that provide valuable biological information [36,40,41]. Principal component analysis (PCA) is a tool used to explore the data (identification of trends and patterns within the data), leading to the generation of predictive models [40,42]. PCA models were computed from both ESI positive and negative data to provide a visual evaluation of the tomato plant tissues (roots, stems, and leaves) responding to $P$. capsici inoculation. This showed time-related clustering of the various samples (Figure 3A and Figures S6A-S10A), equating to metabolic reprogramming. Furthermore, the pooled biological quality control (BPQC) samples clustered in the middle of the PCA scores plot, reflecting the UHPLC-MS stability, reliability, and reproducibility of the data acquired. The PCA-extracted trends and patterns were further examined by hierarchical clustering $(\mathrm{HC})$ analysis to build clusters. The HC models were computed with Ward's linkage method considering "between" and "within" cluster distances, and the trees were sorted based on size [43-45]. The computed HC models displayed time-dependent sub-clustering (Figure 3B and Figures S6B-S10B). Both PC and HC analyses thus revealed the overall structure of the data, showing underlying trends and patterns in the acquired data sets. These observations clearly indicate the time-dependent metabolic reprogramming in the various tomato tissues in response to $P$. capsici inoculation.

To complement the exploratory data provided by PCA (Figure 3A and Figures S6A-S10A) and HC analysis (Figure 3B and Figures S6B-S10B) models, a predictive model, orthogonal-partial least square discriminant analysis (OPLS-DA), was used to evaluate and explain the metabolic reprogramming occurring in tomato plants in response to P. capsici infection. The computed OPLS-DA models (Figure 4A and Figures S11A-S15A) show a clear separation of control plants (NT day 8) from the treated samples (PC day 6), thus indicating different metabolic profiles. PC day 6 was chosen based on the development of the symptoms; on day 8 the plants were already dying, and to avoid responses not related to the infection, day 6 was chosen. The OPLS-DA models were validated using the $R^{2}$ and $\mathrm{Q}^{2}$ metrics, and the analysis of variance testing for cross-validated predictive residuals (CV-ANOVA, $p$-value $<0.05$ indicates a good model) [41,46]. 

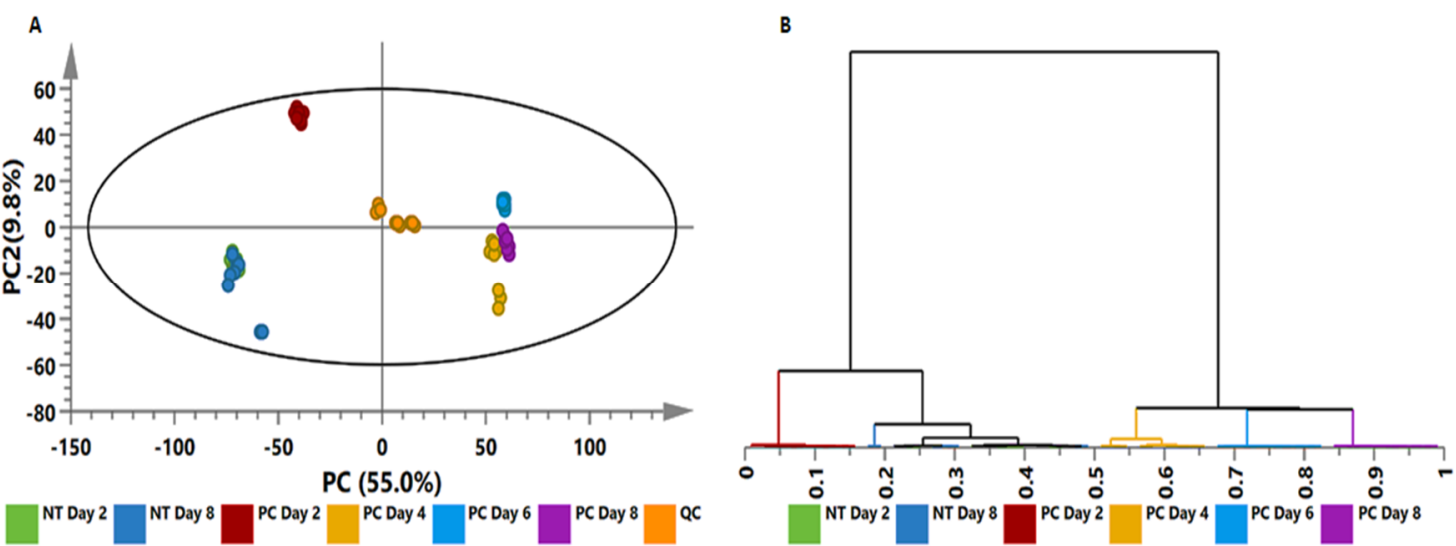

Figure 3. Unsupervised statistical analysis of tomato plants infected with Phytophthora capsici; leaf data acquired in electrospray ionisation $\left(\mathrm{ESI}^{-}\right)$mode. (A): A principal component analysis (PCA) scores scatter plot of all the samples, including the quality control (QC) samples, coloured according to time points. The PCA model presented here was a 7-component model, with $\mathrm{R}^{2}$ of 0.801 and $\mathrm{Q}^{2}$ of 0.737. (B): The hierarchical clustering (HC) dendrogram corresponding to (A). Unsupervised statistical analysis was used to generate subgrouping of samples based on similar observations in (A), while the HC dendrogram shows the hierarchical relationship between samples (B). Similar figures (both for $\mathrm{ESI}^{-}$and ESI ${ }^{+}$modes) were generated for stem and root tissue and are presented as Figures S6A-S10A. NT $=$ non-treated and $\mathrm{PC}=P$. capsici-treated/stem inoculated .
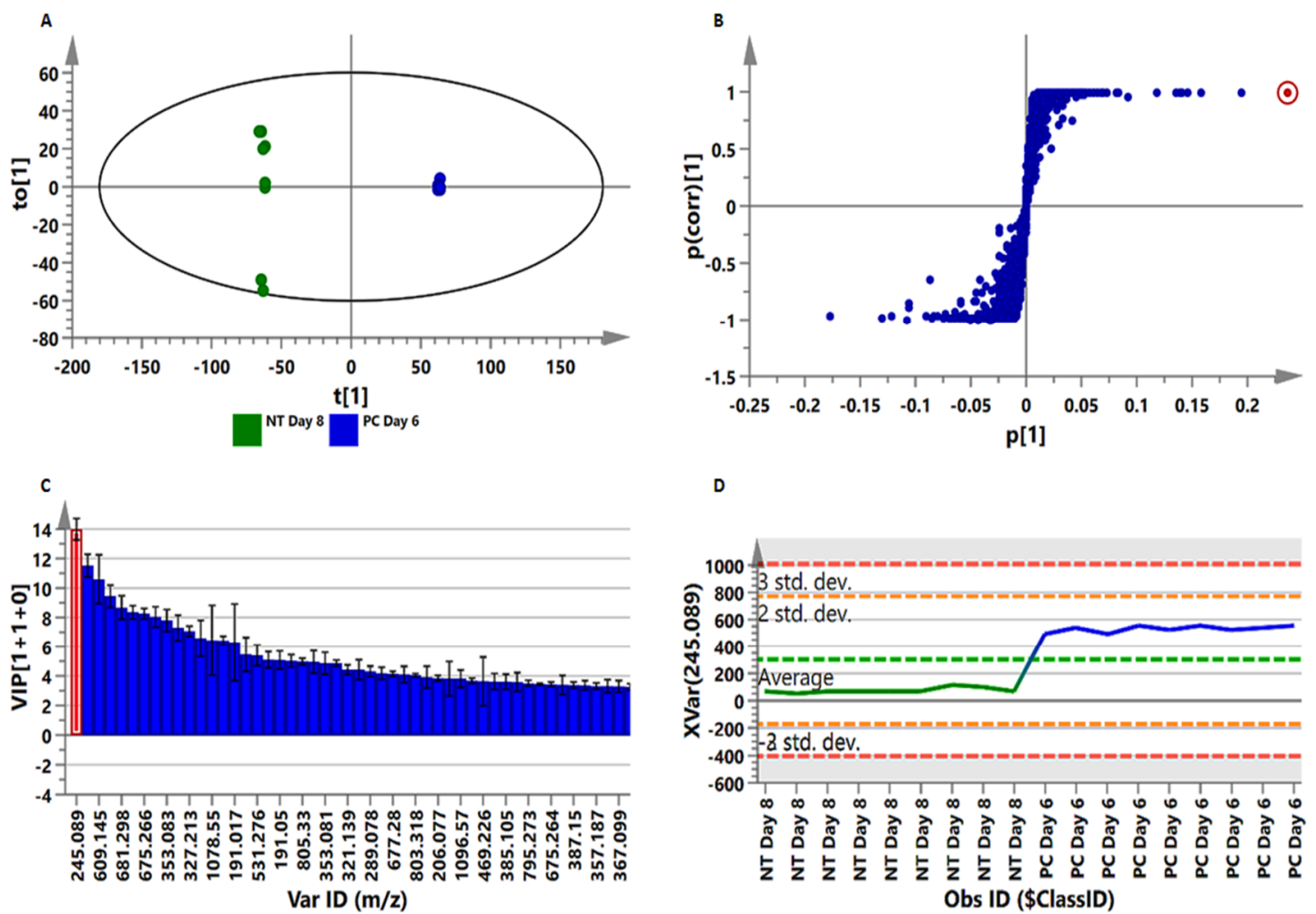

D

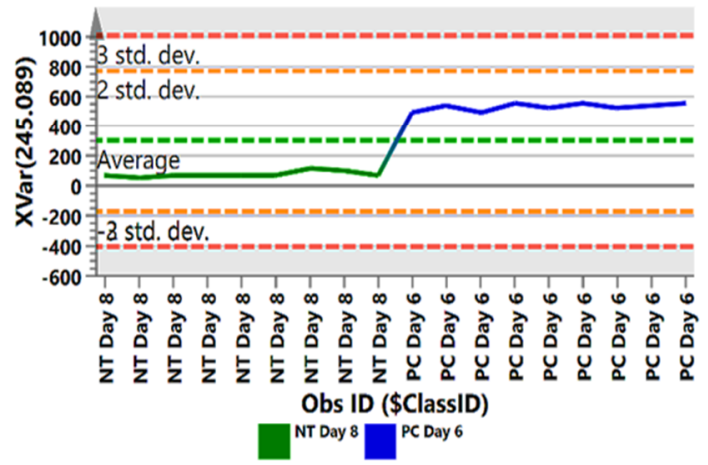

Figure 4. Orthogonal-partial least square discriminant analysis (OPLS-DA) modelling and variable/feature selection of tomato plants infected with Phytophthora capsici; leaf data acquired in $\mathrm{ESI}^{-}$mode. (A): A typical OPLS-DA score plot separating non-treated (NT) day 8 plants vs. P. capsici (PC)-treated day 6 plants $(1+1+0)$ components, $\mathrm{R}^{2} \mathrm{X}=0.802, \mathrm{Q}^{2}=0.999, \mathrm{CV}$-ANOVA $p$-value $\left.=1.3 \times 10^{-19}\right)$. (B): An OPLS-DA loadings S-plot for the same model in A; only variables with the correlation [ $(p($ corr $)]$ $\geq|0.6|$ and covariance $(p 1) \geq|0.05|$ were chosen as discriminating variables, and identified using the $\mathrm{m} / \mathrm{z}$ 
to generate an elemental composition. (C): A variable importance in projection (VIP) plot for the same model, pointing mathematically to the importance of each variable in contributing to group separation in the OPLS-DA model. (D): A typical variable trend plot (of the selected variable in VIP and S-plots), displaying the changes of the selected variables across the samples (NT day 8 vs. PC day 6). This shows that the selected features significantly discriminated the treated from the control samples. Similar figures (both $\mathrm{ESI}^{-}$and $\mathrm{ESI}^{+}$) were generated for stem (site of inoculation) and root tissue, presented as Figures S11-S15.

For extraction of the signatory biomarkers responsible for the observed sample separation on OPLS-DA, the loadings S-plot (a selection method for variables) (Figure 4B and Figures S11B-S15B) was used for feature selection. To validate the significance of the latter, variable importance in projection (VIP) plots (Figure 4C and Figures S11C-S15C) were used, and variables with a score of $>1$ were considered as significant (and subsequently selected for compound annotation). VIP plot evaluation prevents bias in the selection of variables, and helps to describe the importance of the variables to the model [41]. Lastly, a variable trend plot (Figure 4D and Figures S11D-S15D) of the S-plot and VIP plot selected variable (highlighted in red) was computed to evaluate the change of the selected feature across the samples (NT vs. PC). Various models (both PCA and OPLS-DA), comparing the metabolomes from different days (PC day 2-8) against controls (NT days 2 and 8) were generated. Due to the large number of graphs generated, not all can be shown. The features found to distinguish NT from PC were then selected for compound annotation. Owing to the lack of commercially available authentic standards, annotations represent putative identifications with assigned features at a metabolite identification (MSI) level-2 annotation [47,48], and are summarised in Table S1, according to retention time (Rt), ESI mode, $m / z$, empirical formula, and diagnostic fragments.

\subsubsection{Correlation Analysis of OPLS-DA-Derived Features from Control and Infected Tomato Plants}

Following the annotation of significant features highlighted by OPLS-DA, Pearson correlation coefficient analysis was used to analyse the metabolite-metabolite correlation among identified molecules in NT day 8, and PC day 6 plants (Figure 5). Correlation measures the direction and strength of a linear relationship in bivariate data. Variables can be either positively/negatively correlated or not show any correlation. The former is a relationship where two variables move tandemly (one variable increases or decrease, and so does the other) and negative correlation is an inverse relationship between bivariate data (higher values of one variable are associated with lower values of the other). Thus, it allows identification of related metabolites in extracts from NT day 8 and PC day 6 plants. Fifty five significant metabolites were annotated in the different tissues (root, stem, and leaf) and metabolite-metabolite correlation of these significant biomarkers between NT day 8 and PC day 6 showed a unique profile in different samples (Figure 5).

Notably, positive and negative correlation was observed between metabolites derived from the same biochemical pathway, but also between metabolites in entirely different pathways. For example in root tissue (Figure S17) the amino acids Phe and Pro have a strong positive correlation $(r=1)$. Furthermore, these amino acids have a positive correlation with dehydro-tomatine I and dihydro-benzoic acid pentose, but a negative correlation with acetyl Trp (Figure S17). In stem tissue, Pro and Trp have a positive correlation, but have a strong negative correlation with Phe and N-Acetyl-Asp (Figure S16). In addition, chlorogenic acids (cis-4-CQA and trans-3CQA) have a strong positive correlation. However, these molecules have a strong negative correlation with two other hydroxycinnamic acid (HCA) conjugates, (feruloyl-tyramine and feruloyl-agmatine II) (Figure S16). A similar trend was also observed in leaf tissue (Figure 6). Here, flavonoids, kaempferol-3-O-B-rutinoside and quercetin-3-O-trisacharide, are positively correlated $(r=1)$ but are negatively correlated with salicylic acid glycoside and Phe (Figure 6). These results are in accordance with the notion that plants fine-tune their immune response based on the perceived stimulus. Furthermore, the metabolomics data reflects a complex/dynamic feedback mechanism caused by modulation (inhibition/activation) of enzymes involved in the production of metabolites in the same pathway or in different pathways. 


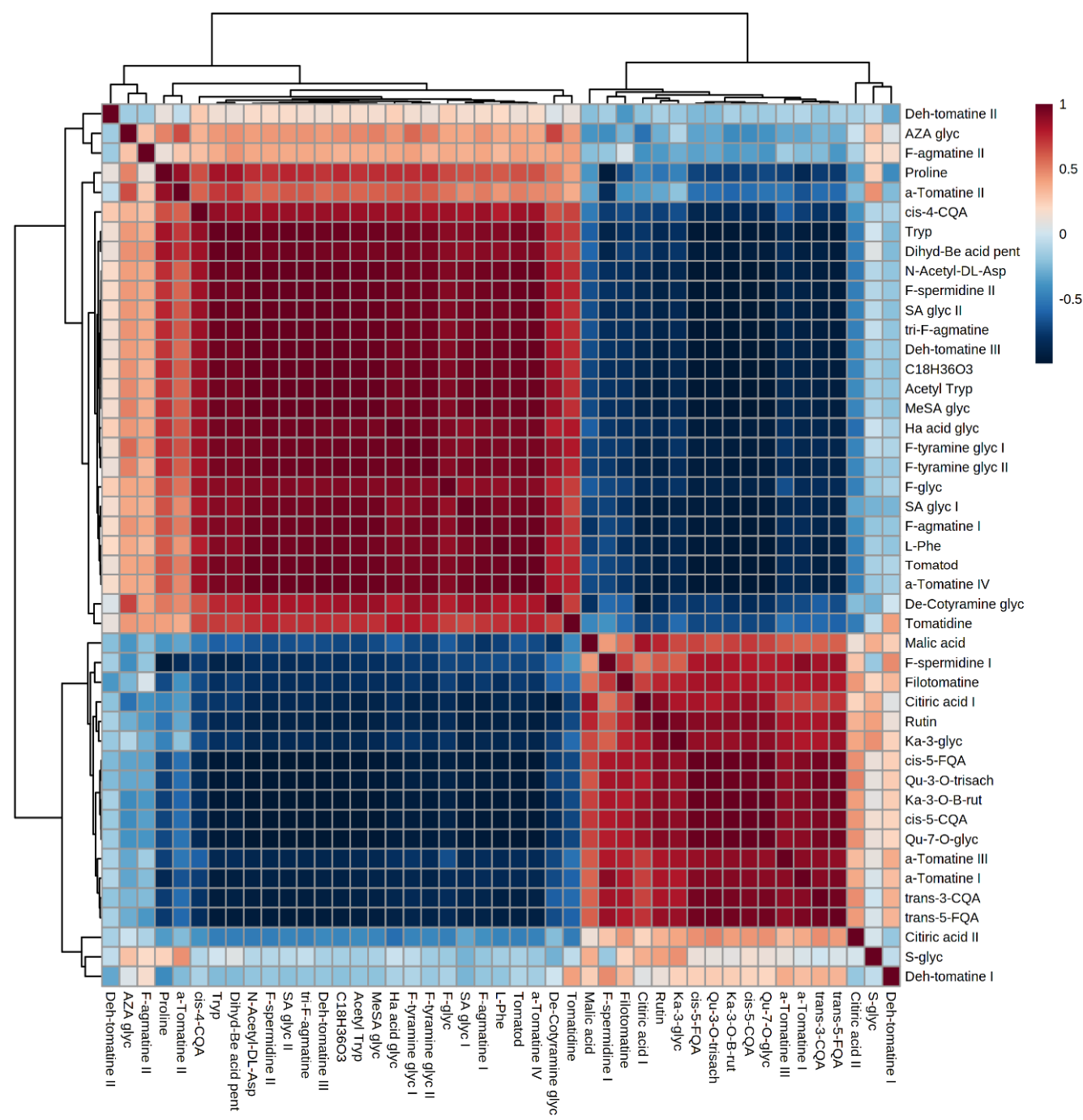

Figure 5. Correlation matrix among the changes $(\Delta)$ within/between extracts from leaves of non-treated (NT) day 8 tomato plants and Phytophthora capsici (PC)-treated plants at day 6 post-inoculation. Metabolite-metabolite correlations among identified molecules were obtained by deriving a Pearson correlation coefficient. Red indicates a positive correlation, and blue indicates a negative correlation. Abbreviations are explained in Table S1. Dendrograms are shown on the top and left of the correlation, indicating clustering of positive and negative correlations. The equivalent matrices for extracts from stems (site of inoculation) and roots are shown in Figures S16 and S17 respectively.

\subsubsection{Time-Course of Comparative Metabolite Reprogramming in P. capsici-Infected Tomato Plants}

To further mine the data, and in order to derive greater biochemical insights into the underlying biochemistry of the host response to infection, PLS-DA was computed to investigate time-dependent metabolic reprogramming of infected plants. To determine the response of each feature to $P$. capsici infection, measurements of selected metabolites (VIP score $\geq 0.5$ ) in infected plants were compared to those in control plants at the given time point, and observed a differential metabolic reprogramming (Figure 6). This resulted in pinpointing a total of 30 reprogrammed metabolites over a time period of 8 days. These belonged to the classes of flavonoids, fatty acids, amino acids, TCA intermediates, glycoalkaloids, and HCA derivatives, representing the core metabolome responsive to $P$. capsici infection. These discriminant molecular features of Figure 6 are in accordance with the ions depicted in the S-plots derived from the OPLS-DA models (Figure 4A and Figures S11A-S15A), and further explain the time-dependent clustering observed in the PCA (Figure 3A and Figures S6A-S10A) and HC analysis (Figure 3B and Figures S6B-S10B) models. 


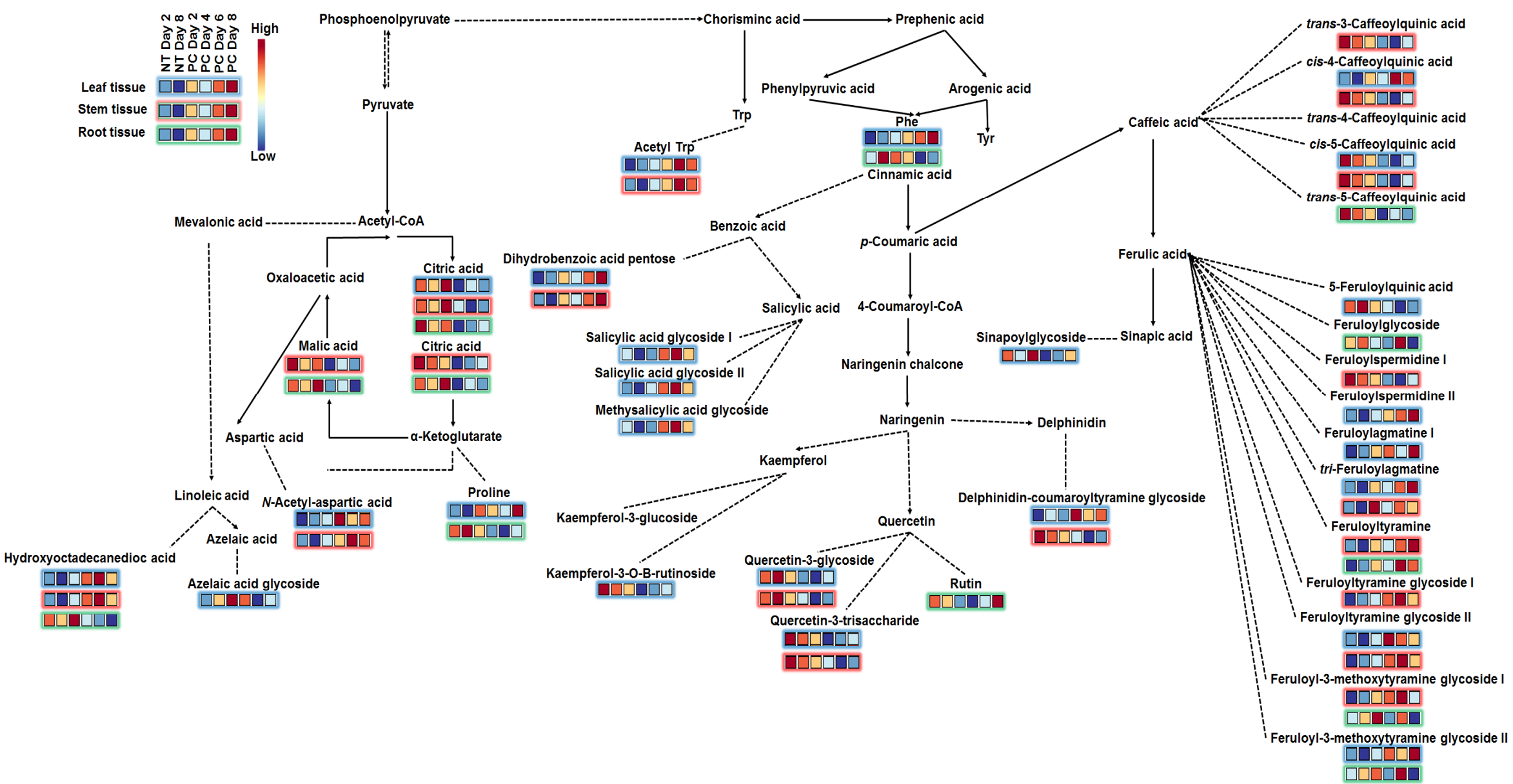

Figure 6. Metabolic changes in Phytophthora capsici-infected plant tissues (roots, stems, and leaves) over the time period of 2-8 d.p.i. Selected metabolites (VIP score $\geq 0.5$ ) in infected plants were compared to those in control plants at the given time point. Blue boxes indicate down regulated metabolites/associated with the control, while red boxes indicate up regulated metabolites/associated with the treatment. Solid lines with an arrow indicate a single reaction, dotted lines with an arrow indicate multiple reactions, and dotted lines with no arrows indicated conjugation. NT $=$ non-treated and PC $=P$. capsici, (stem-inoculated). 
Differential Reprogramming in Primary Metabolism

The host response of the tomato plant to P. capsici treatment exhibited a contrasting metabolic reprogramming in the different tissues and in the regulated pathways (Figures 5 and 6, Figures S16 and S17). Using the MS and MS/MS spectra, three amino acids (Pro, Phe, and Trp), two amino acid derivatives (N-acetyl-tryptophan and $\mathrm{N}$-acetyl-aspartic acid), and two organic acids (citric acid I/II and malic acid), derived from the TCA cycle, were annotated (Figure 6). The two citric acids were found in all tissues and decreased with disease progression in root and stem tissue, whereas in leaf tissue, citric acid I increased with disease progression, and citric acid II decreased. In addition, the TCA cycle led to the production of fatty acids, and one oxygenated fatty acid (octadecanoic acid derivative) was annotated. $\mathrm{C}_{18} \mathrm{H}_{36} \mathrm{O}_{3}$ was found in all tissues (Figure 6). In both leaf and stems $\mathrm{C}_{18} \mathrm{H}_{36} \mathrm{O}_{3}$ was found to increase with disease progression, with maximum content on day 6 (Figure 6), whereas the opposite was observed in roots.

Differential Reprogramming of Phytohormones and Signalling Molecules

Azelaic acid (Aza)-glycoside was identified in both stem and leaf tissue on day 6 post-inoculation (Figure 6). However, the VIP score was 0.5 in both tissues, hence no time-trend was observed. One salicylic acid-glycoside (SAG) was found in stems, while in leaves two SAGs and methyl salicylic acid glycoside (MeSAG) were annotated. Furthermore, a time-trend could only be observed in leaf tissue, and all three molecule showed an increase during disease progression. SA is a well-documented phytohormone responsible for resistance induction following pathogen infection, and MeSA is the volatile derivative, able to move systemically and trigger distal responses $[11,13]$.

Differential Reprogramming of Flavonoids and Hydroxycinnamic Acid Derivatives

The results revealed flavonoids as signatory biomarkers during $P$. capsici infection, and were shown to be reduced in infected plants (Figure 6). Flavonoids are phenolic molecules that play various functions in plants (e.g., signalling, antioxidant, biotic, and abiotic stress resistance) and their occurrence in plants during plant defences is geared toward protective and defence activities. HCA derivatives were annotated as discriminant biomarkers, and found to be conjugated to sugars, polyamines, and quinic acids (Figure 6). Furthermore, these molecules showed a contradicting content (decrease or increase) during pathogen infection.

\section{Differential Reprogramming of Glycoalkaloids}

Glycoalkaloids were identified among the annotated significant features/discriminatory biomarkers, and time-differential accumulation was observed (Figure 7). For example in roots, the content of these molecules was found to be high at different time points, or high on day 2, and then decreased thereafter. Similar trends were observed in both stem and leaf tissues.

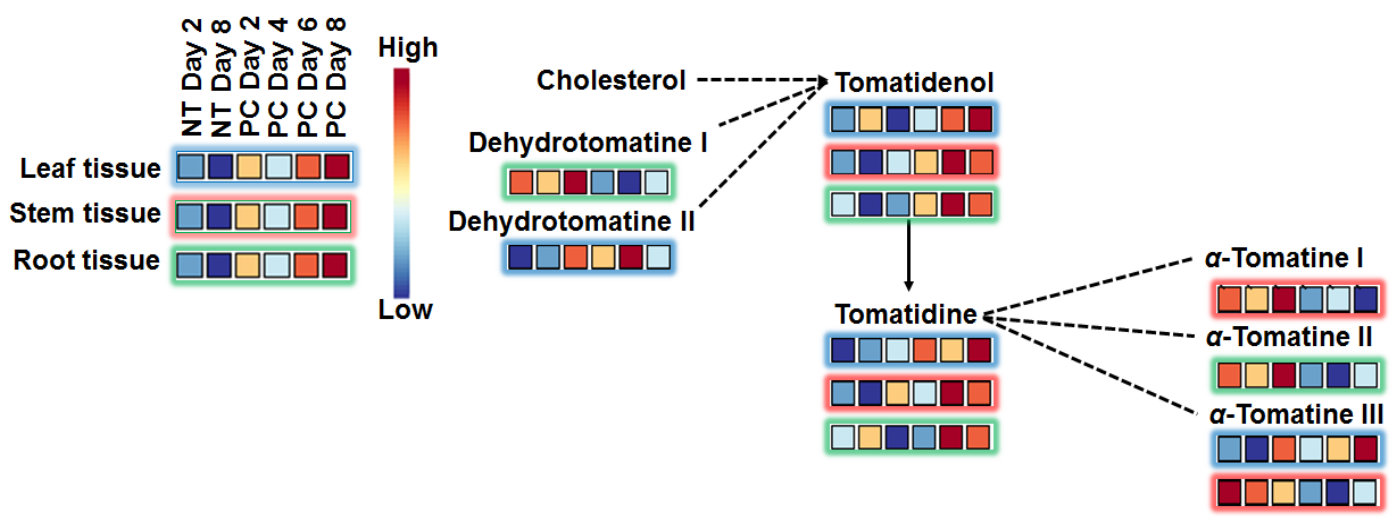

Figure 7. Metabolic changes in glycoalkaloid pathway in Phytophthora capsici-infected tomato tissues over the time-period of 2-8 d.p.i. Selected metabolites (VIP score $\geq 0.5$ ) in infected plants were compared 
to those in control plants at the given time point. Blue boxes indicate down regulated metabolites/ associated with the control, while red boxes indicate up regulated metabolites/associated with the treatment. Solid lines with an arrow indicate a single reaction, dotted lines with an arrow indicate multiple reactions, and dotted lines with no arrows indicate conjugation. NT = non-treated and PC $=$ P. capsici (stem-inoculated).

\section{Discussion}

P. capsici is a hemibiotrophic pathogen with an initial biotrophic phase, followed by a switch to a necrotrophic lifestyle [1-3]. It is not known what triggers this switch (e.g., stress signals originating from the host). Following establishment of a successful biotrophic infection at the initial site of inoculation, localised defense responses are triggered, which may elicit further/subsequent systemic responses. While biotrophy is associated with SA-mediated plant defense, the switch to necrotrophy (depending on penetration into the endodermis and vasculature and movement along the xylem) leads to cell death, and production of ethylene and jasmonic acid, and derivatives [2,3,49]. Moreover, cell death of the roots and stems will limit or prevent transfer of water and solutes to the foliage. The observed wilting symptoms of the leaves may therefore be associated with abiotic stress responses, superimposed on the biotic stress responses. It is therefore conceivable that the differential perturbations to the metabolomes of the roots, stems, and leaves are the refection of different stimuli, and that the tissue-specific changes in the leaves might be due to a combination of biotic and abiotic stresses.

Plant primary metabolism plays an important role in plant-pathogen interactions. Previous studies have shown that primary metabolites are "energy-reservoirs" for plant defence, and serve as precursors for secondary metabolite biosynthesis $[25,27,50]$. Among the different primary metabolites known to be involved in plant-pathogen interactions, amino acids are the most well-documented, and have been shown to be significantly modulated $[27,51]$. In the context of defence, aromatic amino acids synthesised from chorismate through the shikimate pathway, are especially important (Figure 1). These amino acids serve as a link to secondary metabolism as a source of important precursors, with regard to phenolic compound biosynthesis and lignin accumulation [51-53]. Metabolite profiling in Arabidopsis thaliana inoculated with an avirulent strain of Pseudomonas syringae pv. tomato DC3000 (hrp- mutant) revealed an increase in Trp, Tyr, Lys, Val, and Leu content, and a decrease in Glu, whereas inoculation with the virulent strain showed an increase in Ileu, Thr, Ala, Phe, Tyr, and Gln accumulation [54]. In addition, amino acids were found to be significantly affected by Rhizoctonia solani infection on various rice lines [55], as well as in tomato basal resistance and priming against Botrytis cinerea and Ps. syringae [56].

Pro is known to accumulate in plants in response to water and salt stress, where it functions as an osmolyte and protein stabiliser [57]. However, in this study, control plants had a high(er) content of Pro than infected plants (Figure 6), thus suggesting that Pro could be playing a different role than that under abiotic stresses. In this instance, Pro is used as a precursor for the biosynthesis of other molecules (providing both carbon and nitrogen) or is metabolised [58]. Phe belongs to the aromatic amino acid group and serves as a precursor for the phenylpropanoid pathway. Trp and its derivative (acetyl Trp) are involved in biosynthesis of indoles such as auxin [32,51], serotonin, and its HCA amides [59], which are known to play various functions during plant defence responses. This pathway produces numerous metabolites known to play major roles in plant defence response [52,60,61]. N-acetyl-Asp was only found in leaves and showed an increase during pathogen progression. In this regard, amino acid conjugation to other molecules is well documented; these can conjugate to phytohormones, and this has been found to be the regulatory hub of plant defence response [58].

Organic acids are carbon providers for the biosynthesis of metabolites and are intermediates of the TCA cycle [62]. In this study, citric, and malic, acids were annotated as biomarkers. Interestingly, tricarboxylates, like citric acid and fumaric acid, were reported to induce defense priming against bacteria in Arabidopsis thaliana [63]. The TCA cycle is a central metabolic pathway for aerobic processes, and is responsible for a major portion of carbohydrate, fatty acid, and amino acid oxidation, and which 
produces energy and reducing power $[64,65]$. The involvement of fatty acids in plant defence responses is still poorly understood. However, the molecules could be related to lipid signalling or precursor synthesis for later lipid peroxyl radical production, or membrane destruction accompanied with plant cell death infection [66]. In this context, an oxygenated fatty acid (octadecanoic acid derivative) was annotated. $\mathrm{C}_{18} \mathrm{H}_{36} \mathrm{O}_{3}$ was found in all tissues (Figure 6), and increased with disease progression in both leaf and stems.

Plant defence responses are highly regulated by phytohormones and the related signalling molecules [67,68]. SA and its derivative MeSA (Figure 2A), are key phytohormones, especially relevant for local and systemic acquired resistance (SAR) [11,13]. Due to its volatility, MeSA deserves special attention, as it can diffuse through membranes, thus activating systemic responses $[67,69,70]$. Similarly, ET is readily diffusible in plant tissues, exerting effects at very low concentrations. The gaseous state of ET makes it difficult to quantify, however, quantification of the precursor, ACC (Figure 2B), has been used to study ethylene perturbation by microbes or environmental stresses [71-75]. Moreover, some studies suggest that ACC also regulates plant development and defence responses [76,77]. Upon infection, these phytohormones accumulate at the site of ingress and are transported to non-infected plant parts where they activate defence responses [68,70]. It is of interest that MeSA concentrations were the highest in the stems (the site of inoculation, and where initial biotrophic growth will occur), while those of ACC (associated with necrotrophic growth) were the highest in the leaves. Previous studies have demonstrated that plant infection leads to reprogramming of phytohormone homeostasis (decrease or increase phytohormones) [21,72,73]. Infection of $A$. thaliana plants by three fungal pathogens Alternaria brassicicola, Colletotrichum higginsianum, and Botrytis cinerea caused minor effects on MeSA and ACC levels [73]. Moreover, studies have shown the ability of fungal pathogens such as Botrytis cinerea, Ustilago maydis, P. sojae, and Magnaporthe oryzae to suppress phytohormone signalling by different mechanisms. These include conversion of phytohormones to inactive products or degradation of precursors [78].

Chemometric analyses revealed a significant accumulation of the phytohormones azelaic acid-glycoside, salicylate-glucoside, and methyl salicylic acid glucoside (Figure 6) as a differentiating characteristic of the defence responses of tomato plants to P. capsici infection. Phytohormones coordinate multiple physiological and biochemical processes, such as plant growth and development, gene regulation, and responses to abiotic and biotic stresses [4,79]. Aza is an emerging plant signalling molecule involved in SAR induction and regulation, and acts to confer resistance in both local and distal plant tissue [80]. The accumulation of various Aza derivatives including Aza-glycoside in lipopolysaccharide (LPS)-treated tobacco cell suspensions was reported [81], and the presence of Aza-glucosyl transferase(s), involved in Aza glycosylation, was proposed. The accumulation of Aza-glycoside in stem (site of infection) and leaf (distal) tissue, emphasises the link between local and distal signalling. Glycosylation of aglycones could serve both a regulatory and transport function. SA can be methylated to produce the mobile form MeSA, which can be transported to distal tissues, where it is demethylated to SA $[13,81,82]$. Studies have indicated that, after successful defence, the free active SA is glycosylated into inactive SAG, and the less abundant SA-derivative salicyloyl glucose ester (SAGE) by SA glucosyl transferases for storage [81,83].

Flavonoid compounds may accumulate in high quantities during pathogen infection [84]. Some metabolic studies have shown that tomato plants infected with B. cinerea had a higher content of flavonoids compared to non-infected plants [56]. In addition, in potato plants, accumulation of flavonoids was associated with resistance against late blight caused by $P$. infestans [85]. However, the results for $P$. capsici infected tomato showed a general decrease in flavonoid content during pathogen progression (Figure 6); an unexpected phenomenon that has not been well-described in the literature. This decrease in flavonoid content could be associated with defence response specificity (plants use similar pathways to defend against pathogens, albeit differently), re-channelling of HCA precursors for biosynthesis of other molecules such as phytoalexins or incorporation to the cell wall $[2,61,84]$. If not 
replenished, levels of flavonoids can also exhibit a decrease, if degraded by the pathogen, or chemically altered due to oxidative environments and antioxidant reactions.

Relatedly, the differential accumulation of HCA derivatives vs. flavonoids is an indication that the metabolic pools change with disease progression, as reported in a study of tomato cultivars responding to Ralstonia solanacearum infection [61]. Defence-related accumulation of HCA derivatives has been well-documented [61]. Ferulic-, caffeic-, $p$-coumaric-, and sinapic-acids are functional antimicrobial compounds, and precursors to the synthesis of both inducible and constitutive defence metabolites. They are also key in structural defences, as monolignol precursors of lignin, and by participating in cross-linking primary cell wall polysaccharides. Furthermore, HCA amides derivatives, such as 4-coumaroylagmatine and feruloylserotonin, annotated in this study, are also known in the context of cell wall strengthening, as well as antimicrobial compounds [86].

Glycoalkaloids occur naturally in tomato plants [66]; however, studies have shown that these molecules have antimicrobial properties against various plant pathogens, suggesting a major role in disease resistance $[2,61]$. Tomatidine is an interesting biomarker (Figure 7) because of the ability of bacteria and fungi to remove one or more sugar residues, thus rendering it less toxic. It is a well-known fact that microbes have evolved to suppress plant defence responses. Genes encoding glycoside hydrolases with potential activity against glycoalkaloids have been proposed in P. infestans, while evidence of deglycosylation has been reported [2].

\section{Materials and Methods}

\subsection{Plant Growth Conditions and Treatment with P. capsici}

A virulent strain of Phytophthora capsici (PRRI 20101) was obtained from the Plant Protection Institute, Agricultural Research Council (ARC), Pretoria, South Africa. Tomato (Solanum lycopersicum var. Moneymaker) seeds were germinated and grown in potted, washed, and autoclaved playpen sand under controlled conditions [87]. The greenhouse conditions were as follow: min temperature $15^{\circ} \mathrm{C}$ and max temperature $28^{\circ} \mathrm{C}$, light/dark cycle of $12 / 12 \mathrm{~h}$, and light intensity of $60 \mu \mathrm{mol} / \mathrm{m}^{2} / \mathrm{s}$. Watering and fertiliser application were done on a weekly basis. The fertiliser consisted of: $650 \mathrm{mg} / \mathrm{L} \mathrm{CaNO}_{3}$, $400 \mathrm{mg} / \mathrm{L} \mathrm{KNO}_{3}, 300 \mathrm{mg} / \mathrm{L} \mathrm{MgSO}_{4}, 90 \mathrm{mg} / \mathrm{L}$ mono-ammonium phosphate, $90 \mathrm{mg} / \mathrm{L}$ mono-potassium phosphate, $150 \mathrm{mg} / \mathrm{L}$ Soluptase, $20 \mathrm{mg} / \mathrm{L}$ Microples, and $40 \mu \mathrm{L} / \mathrm{L}$ Kep-P-Max, obtained from Shiman (Olifantsfontein, South Africa) [88]. The plants were grown for 8 weeks before infection. P. capsici was grown on potato dextrose agar in Petri dishes at $28^{\circ} \mathrm{C}$ for $5 \mathrm{~d}$. Small triangular pieces were cut from the $5 \mathrm{~d}$ old culture and used to inoculate oatmeal agar. Spores were harvested from 2 week old cultures by cold shocking at $-20^{\circ} \mathrm{C}$ for $20 \mathrm{~min}$ followed by sonication in a sonicating bath for $2 \mathrm{~min}$ and filtration through two layers of Miracloth. Zoospores were microscopically counted using a hemocytometer and adjusted to $1 \times 10^{6} / \mathrm{mL}$ for inoculation with sterile water. The plants were inoculated by pipetting $500 \mu \mathrm{L}$ of the spore solution onto a clean Ventti filter wrapped around a wounded stem. Stems were wounded by cutting a small section with a scalpel blade. Control plants were also wounded and wrapped with a Ventti filter; however, sterile water was used instead of the spore solution. The plants were kept in the growth room, and harvested every second day until the 8th day (PC 2, 4, 6, 8). Since there were no major differences observed in the control plants, control (non-treated) plants were harvested at day 2 and day 8 (NT 2 and NT 8). Three plants were harvested per condition, and each plant was treated as a biological replicate. Together with the three analytical replicates per biological replicate, this generated $n=9$ as required for metabolomic analysis. Following harvesting, the plant tissue (roots, stems, and leaves) were snap-frozen in liquid nitrogen to quench metabolic activity and stored at $-80^{\circ} \mathrm{C}$.

\subsection{Targeted Metabolomics Analysis}

Extraction of Amino Acids and Phytohormones, and UHPLC-QqQ-MS (Ultra High-Performance Liquid Chromatography Triple Quadrupole Mass Spectrometry) Analysis. 
Following homogenisation of roots, stems, and leaf tissues, extraction was carried out as previously described [87]. The filtered $1.5 \mathrm{~mL}$ samples were analysed on a Nexera UHPLC (Shimadzu Corporation, Kyoto, Japan), fitted with a Restek Ultra AQ C18 column $(100 \mathrm{~mm} \times 2.1 \mathrm{~mm} \times 3 \mu \mathrm{m})$ thermostatted at $40{ }^{\circ} \mathrm{C}$, and coupled to a Shimadzu triple quad mass spectrometer (QqQ-MS) (Shimadzu Corporation, Tokyo, Japan). Chromatographic and mass spectrometry conditions were as previously described [87]. An internal standard of $1 \mathrm{ng} / \mu \mathrm{L}$ prednisolone (Pred) was included in the samples to monitor the instrument reliability and data acquisition reproducibility. LC-MS data acquisition was carried out in triplicate, and the results were expressed as mean values \pm standard deviation (SD). Univariate analysis of variance (ANOVA) was performed as 2-tailed complete randomised blocks, and used to compare the non-infected vs. P. capsici-inoculated plants at different time points. ANOVA was followed by the Tukey post-hoc test, where differences between the means were considered significant at $p<0.05$, indicated in graphs with an asterisk $\left(^{*}\right)$ or a $\operatorname{dot}(\bullet)$. The summarised outputs are presented in Tables S2 and S3.

\subsection{Non-Targeted Metabolomics Analysis}

4.3.1. Metabolite Extraction and Data Acquisition on an UHPLC-ESI-qTOF-MS (Ultra High-Performance Liquid Chromatography, Electrospray Ionisation, Quadrupole Time-of-Flight Mass Spectrometry)

Metabolite extraction and sample preparation were carried out as described [87]. The final filtered extracts were reconstituted to $300 \mu \mathrm{L}$ (stems and leaves) and $250 \mu \mathrm{L}$ (roots) in $50 \%$ methanol. A pooled biological quality control (PBQC) sample was prepared by pipetting and mixing aliquots of equal volumes from the samples. The samples were analysed in triplicate on an UHPLC system (Waters Acquity HSS T3 C18 column, $150 \mathrm{~mm} \times 2.1 \mathrm{~mm} \times 1.8 \mu \mathrm{m}$, thermostatted at $60{ }^{\circ} \mathrm{C}$ ), coupled to high-definition MS (UHPLC-HD-MS), controlled and operated by MassLynx XS ${ }^{\mathrm{TM}}$ software (Waters, Milford, MA, USA). Both LC and MS conditions were as previously described [87] with minor MS setting modifications as follows: desolvation temperature, $450{ }^{\circ} \mathrm{C}$; source temperature, $120^{\circ} \mathrm{C}$; capillary voltage, $2.0 \mathrm{kV}$; sample cone, $35 \mathrm{~V}$; extraction cone, $4.0 \mathrm{~V}$; desolvation gas (Nitrogen) flow, $550 \mathrm{~L} / \mathrm{h}$; cone gas (Nitrogen) flow, $50 \mathrm{~L} / \mathrm{h}$; detector voltage, $1700 \mathrm{~V}$; scan speed, $0.1 \mathrm{sec}$; and interscan time, $0.02 \mathrm{~s}$. PBQCs were used to assess the reliability and reproducibility of the LC-MS system. The samples were randomised and PBQC samples analysed every 10 injections. The MS settings were set to perform unfragmented and five fragmenting experiments $\left(\mathrm{MS}^{\mathrm{E}}\right)$ simultaneously, by ramping in-source collision energy from 3 to $30 \mathrm{eV}[53,89-91]$.

\subsubsection{Multivariate Data Analysis}

The acquired UHPLC-qTOF-MS raw data were pre-processed using MarkerLynx XS ${ }^{\text {TM }}$ software (Waters, Milford, MA, USA), and raw data from both negative and positive modes of electrospray ioninsation (ESI) were analysed. For multivariate modelling the data matrices were created using the following parameters: Rt range, 2.5-25 min; Rt difference, $0.2 \mathrm{~min}$; mass to charge ratio $(\mathrm{m} / \mathrm{z})$ range, 100-2000; $\mathrm{m} / \mathrm{z}$ difference, 0.05; mass tolerance, 0.5; intensity threshold count, 10; and noise level, 3. The pre-processing parameters were adjusted (if needed) depending on visual inspection of the chromatograms. The resultant data matrixes obtained from MassLynx XS were imported into SIMCA-P version 14.0 (Umetrics, Umeå, Sweden), and Pareto scaling was applied for multivariate statistical analysis. Principal component analysis (PCA), an unsupervised method, was used to summarise the information content in the datasets, thus providing "smaller indices" that could be easily visualised and analysed. Orthogonal-partial least square discriminant analysis (OPLS-DA), a supervised method, was used to extract maximum information of significant variables from the datasets. Method validation and variable selection were as described [87].

\subsubsection{Metabolite Annotation}

Significant/discriminant features identified from the multivariate data analysis were annotated as described [87]. In short, a single ion chromatogram for each significant feature was extracted, 
its accurate mass determined, and its corresponding spectrum used to calculate an empirical formula to search in databases such as the Dictionary of Natural Products [92] and ChemSpider [93]. In addition, the spectra were compared with published data.

\subsubsection{Metabolite- Metabolite Correlation and Time-Dependent Reprogramming}

Following annotation of discriminatory markers, the identified metabolites were extracted from the MarkerLynx XS ${ }^{\mathrm{TM}}$ generated matrixes and saved as .csv files. These were uploaded to MetaboAnalyst 4.0 [94] for further statistical analysis. The files comprised a list of experimental conditions, compound names, and intensities. MetaboAnalyst data processing performs checks on data integrity and missing values, and data filter and normalisation, prior to statistical analysis [95,96]. Correlation analysis was performed on non-treated (NT, day 8) and P. capsici (PC)-treated day 6 (based on OPLS-DA observations) samples to investigate the linear relationship between the annotated metabolites. Subsequently, partial least square-discriminant analysis (PLS-DA) (a supervised method) was applied to investigate time-dependent metabolic reprogramming in NT vs. PC-treated plants.

\section{Conclusions}

LC-MS targeted analysis showed a time-dependent regulation of aromatic amino acids as part of the host response of tomato plants in response to infection by P. capsici. The Phe and Trp content increased upon infection, while Tyr increased up to day 4 and gradually decreased thereafter. These findings show the importance of primary metabolites, mainly aromatic amino acids, which are involved in the biosynthesis of phenylpropanoids, flavonoids, and indoles. The increases indicate the demand for phenolic precursors, in comparison to the Tyr decrease, which suggests that the consumption is higher than synthesis. Furthermore, untargeted LC-MS metabolomics analysis showed time-dependent metabolic changes in the non-treated vs. P. capsici-infected plant tissues. The annotated metabolites included phenylpropanoids, benzoic acids, glycoalkaloids, flavonoids, amino acids, and TCA cycle organic acids, as well as oxygenated octadecanoic acids. Metabolite-metabolite correlations showed that there was a dynamic regulation of the programmed metabolites, as evidenced by positive and negative correlation among the significant biomarkers. Lastly, tissue-specific reprogramming was also observed, which demonstrated that various plant tissues (i.e., roots, stems, and leaves) undergo differential metabolomic changes in response to infection. Here, intrinsic tissue-specific profiles would also be influenced by localised infection in the stem, the biotrophy to necrotrophy switch, and the balance between generated signalling molecules, able to trigger systemic responses, as well as possible abiotic stress responses linked to wilting. Regardless, the perturbations of the metabolomes can be interpreted as due to the activation of chemical defences against the pathogen, in an attempt to ward off the infection or limit the cellular damage caused by the infection. The relative importance of the identified metabolic pathways cannot be judged with the available data; however, the identified biomarkers could pave the way for further studies in the tomato response to $P$. capsici infection.

Supplementary Materials: The supplementary materials are available online at http://www.mdpi.com/2218-1989/ 10/11/466/s1.

Author Contributions: Conceptualisation, N.L. and I.A.D.; Formal analysis, M.I.M.; Investigation, M.I.M. and P.A.S.; Methodology, N.L. and M.I.M.; Resources, P.A.S., N.L. and I.A.D.; Supervision, L.A.P. and I.A.D.; Data curation, M.I.M.; Validation, M.I.M.; Writing—original draft preparation, M.I.M.; Writing—review \& editing, L.A.P. and I.A.D. All authors have read and agreed to the published version of the manuscript.

Funding: This research received no external funding.

Acknowledgments: The South African National Research Foundation (NRF), Shimadzu and University of Johannesburg are thanked for fellowship support to M.I.M.

Conflicts of Interest: The authors declare no conflict of interest.

Data Availability: The study design information, LC-MS raw data, analyses and data processing information, and the meta-data were deposited to the EMBL-EBI metabolomics repository MetaboLights50, https://www.ebi.ac. uk/metabolights/MTBLS1176. 


\section{References}

1. Lamour, K.H.; Stam, R.; Jupe, J.; Huitema, E. The oomycete broad-host-range pathogen Phytophthora capsici. Mol. Plant Pathol. 2012, 13, 329-337. [CrossRef] [PubMed]

2. Hardham, A.R. The cell biology behind Phytophthora pathogenicity. Aust. Plant Pathol. 2001, 30, 91-98. [CrossRef]

3. Fawke, S.; Doumane, M.; Schornack, S. Oomycete interactions with plants: Infection strategies and resistance principles. Microbiol. Mol. Biol. Rev. 2015, 79, 263-280. [CrossRef]

4. Denancé, N.; Sánchez-Vallet, A.; Goffner, D.; Molina, A. Disease resistance or growth: The role of plant hormones in balancing immune responses and fitness costs. Front. Plant Sci. 2013, 4, 155. [CrossRef] [PubMed]

5. Conrath, P.G.U.; Beckers, G.J.M.; Flors, V.; García-Agustín, P.; Jakab, G.; Mauch, F.; Newman, M.; Pieterse, C.M.J.; Poinssot, B.; Pozo, M.J.; et al. Priming: Getting ready for battle. Mol. Plant Microbe Interact. 2009, 19, 1062-1071. [CrossRef]

6. Qi, Y.; Tsuda, K.; Glazebrook, J.; Katagiri, F. Physical association of pattern-triggered immunity (PTI) and effector-triggered immunity (ETI) immune receptors in Arabidopsis. Mol. Plant Pathol. 2011, 12, 702-708. [CrossRef]

7. Liu, W.; Liu, J.; Ning, Y.; Ding, B.; Wang, X.; Wang, Z.; Wang, G.L. Recent progress in understanding PAMPand effector-triggered immunity against the rice blast fungus Magnaporthe oryzae. Mol. Plant 2013, 6, 605-620. [CrossRef]

8. Newman, M.A.; Sundelin, T.; Nielsen, J.T.; Erbs, G. MAMP (microbe-associated molecular pattern) triggered immunity in plants. Front. Plant Sci. 2013, 4, 139. [CrossRef]

9. Müller, M.; Munné-Bosch, S. Rapid and sensitive hormonal profiling of complex plant samples by liquid chromatography coupled to electrospray ionization tandem mass spectrometry. Plant Methods 2011, 7, 37. [CrossRef]

10. Suarez-Rodriguez, M.C.; Adams-Phillips, L.; Liu, Y.; Wang, H.; Su, S.H.; Jester, P.J.; Zhang, S.; Bent, A.F.; Krysan, P.J. MEKK1 is required for flg22-induced MPK4 activation in Arabidopsis plants. Plant Physiol. 2007, 143, 661-669. [CrossRef]

11. Dempsey, D.A.; Klessig, D.F. SOS-Too many signals for systemic acquired resistance? Trends Plant Sci. 2012, 17, 538-545. [CrossRef] [PubMed]

12. Jia, C.; Zhang, L.; Liu, L.; Wang, J.; Li, C.; Wang, Q. Multiple phytohormone signalling pathways modulate susceptibility of tomato plants to Alternaria alternata f. sp. lycopersici. J. Exp. Bot. 2013, 64, 637-650. [CrossRef] [PubMed]

13. Dempsey, D.A.; Klessig, D.F. How does the multifaceted plant hormone salicylic acid combat disease in plants and are similar mechanisms utilized in humans? BMC Biol. 2017, 15, 23. [CrossRef] [PubMed]

14. Pieterse, C.M.J.; Leon-Reyes, A.; Van Der Ent, S.; Van Wees, S.C.M. Networking by small-molecule hormones in plant immunity. Nat. Chem. Biol. 2009, 5, 308-316. [CrossRef] [PubMed]

15. Tugizimana, F.; Steenkamp, P.A.; Piater, L.A.; Dubery, I.A. Multi-platform metabolomic analyses of ergosterol-induced dynamic changes in Nicotiana tabacum cells. PLoS ONE 2014, 9, 87846. [CrossRef] [PubMed]

16. Balmer, D.; Flors, V.; Glauser, G.; Mauch-Mani, B. Metabolomics of cereals under biotic stress: Current knowledge and techniques. Front. Plant Sci. 2013, 4, 82. [CrossRef]

17. Glazebrook, J. Genes controlling expression of defense responses in Arabidopsis-2001 status. Curr. Opin. Plant Biol. 2001, 4, 301-308. [CrossRef]

18. De Vos, M.; Van Oosten, V.R.; Van Poecke, R.M.P.; Van Pelt, J.A.; Pozo, M.J.; Mueller, M.J.; Buchala, A.J.; Métraux, J.; Van Loon, L.C.; Dicke, M.; et al. Signal signature and transcriptome changes of Arabidopsis during pathogen and insect attack. Mol. Plant Microbe Interact. 2005, 18, 923-937. [CrossRef]

19. Koornneef, A.; Pieterse, C.M.J. Cross talk in defense signaling1. Plant Physiol. 2008, 146, 839-844. [CrossRef]

20. Verhage, A.; Van Wees, S.C.M.; Pieterse, C.M.J. Plant immunity: It's the hormones talking, but what do they say? Plant Physiol. 2010, 154, 536-540. [CrossRef]

21. Naseem, M.; Dandekar, T. The role of auxin-cytokinin antagonism in plant-pathogen interactions. PLoS Pathog. 2012, 8, 1003026. [CrossRef] [PubMed]

22. Hardham, A.R.; Jones, D.A.; Takemoto, D. Cytoskeleton and cell wall function in penetration resistance. Curr. Opin. Plant Biol. 2007, 10, 342-348. [CrossRef] [PubMed] 
23. Ahuja, I.; Kissen, R.; Bones, A.M. Phytoalexins in defense against pathogens. Trends Plant Sci. 2012, 17, 73-90. [CrossRef] [PubMed]

24. Scheideler, M.; Schlaich, N.L.; Fellenberg, K.; Beissbarth, T.; Hauser, N.C.; Vingron, M.; Slusarenko, A.J.; Hoheisel, D. Monitoring the switch from housekeeping to pathogen defense metabolism in Arabidopsis thaliana using cDNA arrays. J. Biol. Chem. 2002, 277, 10555-10561. [CrossRef]

25. Rojas, C.M.; Senthil-Kumar, M.; Tzin, V.; Mysore, K.S. Regulation of primary plant metabolism during plant-pathogen interactions and its contribution to plant defense. Front. Plant Sci. 2014, 5, 17. [CrossRef]

26. Conrath, U. Molecular aspects of defence priming. Trends Plant Sci. 2011, 16, 524-531. [CrossRef]

27. Bolton, M.D. Primary metabolism and plant defense-Fuel for the fire. Mol. Plant Microbe Interact. 2009, 22, 487-497. [CrossRef]

28. Dixon, R.A.; Paiva, N.L. Stress-induced phenylpropanoid metabolism. Plant Cell 1995, 7, 1085-1097. [CrossRef]

29. Vogt, T. Phenylpropanoid biosynthesis. Mol. Plant 2010, 3, 2-20. [CrossRef]

30. Ballester, A.R.; Lafuente, M.T.; De Vos, R.C.H.; Bovy, A.G.; González-Candelas, L. Citrus phenylpropanoids and defence against pathogens. Part I: Metabolic profiling in elicited fruits. Food Chem. 2013, 136, 178-185. [CrossRef]

31. Widhalm, J.R.; Dudareva, N. A familiar ring to it: Biosynthesis of plant benzoic acids. Mol. Plant 2015, 8, 83-97. [CrossRef] [PubMed]

32. Parthasarathy, A.; Cross, P.J.; Dobson, R.C.J.; Adams, L.E.; Savka, M.A.; Hudson, A.O. A three-ring circus: Metabolism of the three proteogenic aromatic amino acids and their role in the health of plants and animals. Front. Mol. Biosci. 2018, 5, 29. [CrossRef]

33. Spaepen, S.; Vanderleyden, J. Auxin and plant-microbe interactions. Cold Spring Harb. Perspect. Biol. J. 2011, 3, 001438. [CrossRef] [PubMed]

34. Idris, E.E.; Iglesias, D.J.; Talon, M.; Borriss, R. Tryptophan-dependent production of Indole-3-Acetic Acid (IAA) affects level of plant growth promotion by Bacillus amyloliquefaciens FZB42. Mol. Plant Microbe Interact. 2007, 20, 619-626. [CrossRef] [PubMed]

35. Kangasjärvi, S.; Neukermans, J.; Li, S.; Aro, E.M.; Noctor, G. Photosynthesis, photorespiration, and light signalling in defence responses. J. Exp. Bot. 2012, 63, 1619-1636. [CrossRef]

36. Tugizimana, F.; Piater, L.A.; Dubery, I.A. Plant metabolomics: A new frontier in phytochemical analysis. S. Afr. J. Sci. 2013, 109, 18-20. [CrossRef]

37. Xu, Y.; Correa, E.; Goodacre, R. Integrating multiple analytical platforms and chemometrics for comprehensive metabolic profiling: Application to meat spoilage detection. Anal. Bioanal. Chem. 2013, 405, 5063-5074. [CrossRef]

38. Quesada-Ocampo, L.M.; Vargas, A.M.; Naegele, R.P.; Francis, D.M.; Hausbeck, M.K. Resistance to crown and root rot caused by Phytophthora capsici in a Tomato advanced backcross of Solanum habrochaites and Solanum lycopersicum. Plant Dis. 2015, 100, 829-835. [CrossRef]

39. Jupe, J.; Stam, R.; Howden, A.J.M.; Morris, J.A.; Zhang, R.; Hedley, P.E.; Huitema, E. Phytophthora capsici-tomato interaction features dramatic shifts in gene expression associated with a hemi-biotrophic lifestyle. Genome Biol. 2013, 14, R63. [CrossRef]

40. Worley, B.; Halouska, S.; Powers, R. Utilities for quantifying separation in PCA/PLS-DA scores plots. Anal. Biochem. 2013, 433, 102-104. [CrossRef]

41. Tugizimana, F.; Steenkamp, P.; Piater, L.; Dubery, I. A conversation on data mining strategies in LC-MS untargeted metabolomics: Pre-processing and pre-treatment steps. Metabolites 2016, 6, 40. [CrossRef]

42. Worley, B.; Powers, R. Multivariate analysis in metabolomics. Curr. Metab. 2013, 1, 92-107.

43. Gabor, J.S. Hierarchical clustering via joint-within diastances: Extending ward's minimum variance and method. J. Classif. 2005, 22, 151-183. [CrossRef]

44. Fouedjio, F. A hierarchical clustering method for multivariate geostatistical data. Spat. Stat. 2016, 18, 333-351. [CrossRef]

45. Granato, D.; Santos, J.S.; Escher, G.B.; Ferreira, B.L.; Maggio, R.M. Use of principal component analysis (PCA) and hierarchical cluster analysis (HCA) for multivariate association between bioactive compounds and functional properties in foods: A critical perspective. Trends Food Sci. Technol. 2018, 72, 83-90. [CrossRef]

46. Eriksson, L.; Trygg, J.; Wold, S. A chemometrics toolbox based on projections and latent variables. J. Chemom. 2014, 28, 332-346. [CrossRef] 
47. Sumner, L.W.; Samuel, T.; Noble, R.; Gmbh, S.D.; Barrett, D.; Beale, M.H.; Hardy, N. Proposed minimum reporting standards for chemical analysis chemical analysis working group (CAWG) metabolomics standards initiative (MSI). Metabolomics 2013, 3, 211-221. [CrossRef]

48. Creek, D.J.; Dunn, W.B.; Fiehn, O.; Griffin, J.L.; Hall, R.D.; Lei, Z.; Mistrik, R.; Neumann, S.; Schymanski, E.L.; Sumner, L.W.; et al. Metabolite identification: Are you sure? And how do your peers gauge your confidence? Metabolomics 2014, 10, 350-353. [CrossRef]

49. Boevink, P.C.; Birch, P.R.J.; Turnbull, D.; Whisson, S.C. Devastating intimacy: The cell biology of plantPhytophthora interactions. New Phytol. 2020, 228, 445-458. [CrossRef]

50. Karpiński, S.; Szechyńska-Hebda, M.; Wituszyńska, W.; Burdiak, P. Light acclimation, retrograde signalling, cell death and immune defences in plants. Plant Cell Environ. 2013, 36, 736-744. [CrossRef]

51. Tzin, V.; Galili, G. The biosynthetic pathways for shikimate and aromatic amino acids in Arabidopsis thaliana. Arab. Book Am. Soc. Plant Biol. 2010, 8, 0132.

52. Mhlongo, M.I.; Piater, L.A.; Steenkamp, P.A.; Madala, N.E.; Dubery, I.A. Priming agents of plant defence stimulate the accumulation of mono- and di-acylated quinic acids in cultured tobacco cells. Physiol. Mol. Plant Pathol. 2014, 88, 61-66. [CrossRef]

53. Mhlongo, M.I.; Piater, L.A.; Steenkamp, P.A.; Madala, N.E.; Dubery, I.A. Phenylpropanoid defences in Nicotiana tabacum cells: Overlapping metabolomes indicate common aspects to priming responses induced by lipopolysaccharides, chitosan and flagellin-22. PLoS ONE 2016, 11, 0151350. [CrossRef] [PubMed]

54. Ward, J.L.; Forcat, S.; Beckmann, M.; Bennett, M.; Miller, S.J.; Baker, J.M.; Hawkins, N.D.; Vermeer, C.P.; Lu, C.; Lin, W.; et al. The metabolic transition during disease following infection of Arabidopsis thaliana by Pseudomonas syringae pv. tomato. Plant J. 2010, 63, 443-457. [CrossRef]

55. Suharti, W.S.; Nose, A.; Zheng, S.H. Metabolite profiling of sheath blight disease resistance in rice: In the case of positive ion mode analysis by CE/TOF-MS. Plant Prod. Sci. 2016, 19, 279-290. [CrossRef]

56. Camañes, G.; Scalschi, L.; Vicedo, B.; González-Bosch, C.; García-Agustín, P. An untargeted global metabolomic analysis reveals the biochemical changes underlying basal resistance and priming in Solanum lycopersicum, and identifies 1-methyltryptophan as a metabolite involved in plant responses to Botrytis cinerea and Pseudomonas syringae. Plant J. 2015, 84, 125-139.

57. Hayat, S.; Hayat, Q.; Alyemeni, M.N.; Wani, A.S.; Pichtel, J.; Ahmad, A. Role of proline under changing enviromental. Plant Signal. Behav. 2012, 7, 1456-1466. [CrossRef]

58. Zeier, J. New insights into the regulation of plant immunity by amino acid metabolic pathways. Plant. Cell Environ. 2013, 36, 2085-2103. [CrossRef]

59. Ishihara, A.; Hashimoto, Y.; Tanaka, C.; Dubouzet, J.G.; Nakao, T.; Matsuda, F.; Nishioka, T.; Miyagawa, H.; Wakasa, K. The tryptophan pathway is involved in the defense responses of rice against pathogenic infection via serotonin production. Plant J. 2008, 54, 481-495. [CrossRef] [PubMed]

60. Jansen, J.J.; Allwood, J.W.; Marsden-Edwards, E.; Putten, W.H.; Goodacre, R.; Dam, N.M. Metabolomic analysis of the interaction between plants and herbivores. Metabolomics 2008, 5, 150-161. [CrossRef]

61. Zeiss, D.R.; Mhlongo, M.I.; Tugizimana, F.; Steenkamp, P.A.; Dubery, I.A. Metabolomic profiling of the host response of tomato (Solanum lycopersicum) following infection by Ralstonia solanacearum. Int. J. Mol. Sci. 2019, 20, 3945. [CrossRef] [PubMed]

62. Darandeh, N.; Hadavi, E. Effect of pre-harvest foliar application of citric acid and malic acid on chlorophyll content and post-harvest vase life of Lilium cv. Brunello. Front. Plant Sci. 2012, 2, 2011-2013. [CrossRef] [PubMed]

63. Balmer, A.; Pastor, V.; Glauser, G.; Mauch-Mani, B. Tricarboxylates induce defense priming against bacteria in Arabidopsis thaliana. Front. Plant Sci. 2018, 9, 1-15.

64. Fernie, A.R.; Carrari, F.; Sweetlove, L.J. Respiratory metabolism: Glycolysis, the TCA cycle and mitochondrial electron transport. Curr. Opin. Plant Biol. 2004, 7, 254-261. [CrossRef] [PubMed]

65. Garaude, J. Reprogramming of mitochondrial metabolism by innate immunity. Curr. Opin. Immunol. 2019, 56, 17-23. [CrossRef]

66. Zeiss, D.R.; Mhlongo, M.I.; Tugizimana, F.; Steenkamp, P.A.; Dubery, I.A. Comparative metabolic phenotyping of tomato (Solanum lycopersicum) for the identification of metabolic signatures in cultivars differing in resistance to Ralstonia solanacearum. Int. J. Mol. Sci. 2018, 19, 2558. [CrossRef]

67. Kohli, A.; Sreenivasulu, N.; Lakshmanan, P.; Kumar, P.P. The phytohormone crosstalk paradigm takes center stage in understanding how plants respond to abiotic stresses. Plant Cell Rep. 2013, 32, 945-957. [CrossRef] 
68. Shah, J.; Chaturvedi, R.; Chowdhury, Z.; Venables, B.; Petros, R. Signaling by small metabolites in systemic acquired resistance. Plant J. 2014, 74, 645-658. [CrossRef]

69. Manosalva, P.M.; Park, S.W.; Forouhar, F.; Tong, L.; Fry, W.E.; Klessig, D.F. Methyl esterase 1 (StMES1) is required for systemic acquired resistance in potato. Mol. Plant Microbe Interact. 2010, 23, 1151-1163. [CrossRef]

70. Shah, J.; Zeier, J. Long-distance communication and signal amplification in systemic acquired resistance. Front. Plant Sci. 2013, 4, 30. [CrossRef] [PubMed]

71. Lund, S.T.; Stall, R.E.; Klee, H.J. Ethylene regulates the susceptible response to pathogen infection in tomato. Plant Cell 1998, 10, 371-382. [CrossRef] [PubMed]

72. Martínez-Medina, A.; Fernández, I.; Sánchez-Guzmán, M.J.; Jung, S.C.; Pascual, J.A.; Pozo, M.J. Deciphering the hormonal signalling network behind the systemic resistance induced by Trichoderma harzianum in tomato. Front. Plant Sci. 2013, 4, 1. [CrossRef] [PubMed]

73. Riet, K.B.; Ndlovu, N.; Piater, L.A.; Dubery, I.A. Simultaneous analysis of defense-related phytohormones in Arabidopsis thaliana responding to fungal infection. Appl. Plant Sci. 2016, 4, 1600013. [CrossRef] [PubMed]

74. Nascimento, F.X.; Rossi, M.J.; Glick, B.R. Ethylene and 1-aminocyclopropane-1-carboxylate (ACC) in plant-bacterial interactions. Front. Plant Sci. 2018, 9, 114. [CrossRef] [PubMed]

75. Ravanbakhsh, M.; Sasidharan, R.; Voesenek, L.A.C.J.; Kowalchuk, G.A.; Jousset, A. Microbial modulation of plant ethylene signaling: Ecological and evolutionary consequences. Microbiome 2018, 6, 52. [CrossRef] [PubMed]

76. Vanderstraeten, L.; Van Der Straeten, D. Accumulation and transport of 1-aminocyclopropane-1-carboxylic acid (ACC) in plants: Current status, considerations for future research and agronomic applications. Front. Plant Sci. 2017, 8, 38. [CrossRef] [PubMed]

77. Tsang, D.L.; Edmond, C.; Harrington, J.L.; Nühse, T.S. Cell wall integrity controls root elongation via a general 1-aminocyclopropane-1-carboxylic acid-dependent, ethylene-independent pathway. Plant Physiol. 2011, 156, 596-604. [CrossRef]

78. Dieryckx, C.; Gaudin, V.; Dupuy, J.W.; Bonneu, M.; Girard, V.; Job, D. Beyond plant defense: Insights on the potential of salicylic and methylsalicylic acid to contain growth of the phytopathogen Botrytis cinerea. Front. Plant Sci. 2015, 6, 859. [CrossRef]

79. Vlot, A.C.; Dempsey, D.A.; Klessig, D.F. Salicylic acid, a multifaceted hormone to combat disease. Annu. Rev. Phytopathol. 2009, 47, 177-206. [CrossRef]

80. Jung, H.W.; Tschaplinski, T.J.; Wang, L.; Glazebrook, J.; Greenberg, J.T. Priming in systemic plant immunity. Science 2009, 324, 89-91. [CrossRef]

81. Mhlongo, M.I.; Tugizimana, F.; Piater, L.A.; Steenkamp, P.A.; Madala, N.E.; Dubery, I.A. Untargeted metabolomics analysis reveals dynamic changes in azelaic acid- and salicylic acid derivatives in LPS-treated Nicotiana tabacum cells. Biochem. Biophys. Res. Commun. 2017, 482, 1498-1503. [CrossRef] [PubMed]

82. Klessig, D.F.; Tian, M.; Choi, H.W. Multiple targets of salicylic acid and its derivatives in plants and animals. Front. Immunol. 2016, 7, 206. [CrossRef] [PubMed]

83. Dean, J.V.; Mohammed, L.A.; Fitzpatrick, T. The formation, vacuolar localization, and tonoplast transport of salicylic acid glucose conjugates in tobacco cell suspension cultures. Planta 2005, 221, 287-296. [CrossRef] [PubMed]

84. Mareya, C.R.; Tugizimana, F.; Piater, L.A.; Madala, N.E.; Steenkamp, P.A.; Dubery, I.A. Untargeted metabolomics reveal defensome-related metabolic reprogramming in Sorghum bicolor against infection by Burkholderia andropogonis. Metabolites 2019, 9, 8. [CrossRef] [PubMed]

85. Garcia, P.G.; Dos Santos, F.N.; Zanotta, S.; Eberlin, M.N.; Carazzone, C. Metabolomics of Solanum lycopersicum infected with Phytophthora infestans leads to early detection of late blight in asymptomatic plants. Molecules 2018, 23, 3330. [CrossRef]

86. Zeiss, D.R.; Piater, L.A.; Dubery, I.A. Hydroxycinnamate amides: Intriguing conjugates of plant protective metabolites. Trends Plant Sci. 2020, 26. [CrossRef]

87. Mhlongo, M.I.; Piater, L.A.; Steenkamp, P.A.; Labuschagne, N.; Dubery, I.A. Metabolic profiling of PGPR-treated tomato plants reveal priming-related adaptations of secondary metabolites and aromatic amino acids. Metabolites 2020, 10, 210. [CrossRef]

88. Shiman, S.A. Your Trusted Partner in Agriculturtal Remedies. Available online: http://ac.shimansa.co.za (accessed on 21 August 2020). 
89. Madala, N.E.; Tugizimana, F.; Steenkamp, P.A. Development and optimization of an UPLC-QTOF-MS/MS method based on an in-source collision induced dissociation approach for comprehensive discrimination of chlorogenic acids isomers from Momordica plant species. J. Anal. Methods Chem. 2014, 2014, 50879. [CrossRef]

90. Ncube, E.N.; Mhlongo, M.I.; Piater, L.A.; Steenkamp, P.A.; Dubery, I.A.; Madala, N.E. Analyses of chlorogenic acids and related cinnamic acid derivatives from Nicotiana tabacum tissues with the aid of UPLC-QTOF-MS/MS based on the in-source collision-induced dissociation method. Chem. Cent. J. 2014, 8, 66. [CrossRef]

91. Mhlongo, M.I.; Steenkamp, P.A.; Piater, L.A.; Madala, N.E.; Dubery, I.A. Profiling of altered metabolomic states in Nicotiana tabacum cells induced by priming agents. Front. Plant Sci. 2016, 7, 1527. [CrossRef]

92. Dictionary of Natural Products. Available online: www.dnp.chemnetbase.com (accessed on 21 August 2020).

93. Chemspider-Search and Share Chemistry. Available online: www.chemspider.com (accessed on 21 August 2020).

94. MetaboAnalyst-Statistical, Functional and Integrative Analysis of Metabolomics Data. Available online: www.metaboanalyst.ca (accessed on 21 August 2020).

95. Xia, J.; Mandal, R.; Sinelnikov, I.V.; Broadhurst, D.; Wishart, D.S. MetaboAnalyst 2.0—A comprehensive server for metabolomic data analysis. Nucleic Acids Res. 2012, 40, W127-W133. [CrossRef] [PubMed]

96. Xia, J.; Wishart, D.S. Using metaboanalyst 3.0 for comprehensive metabolomics data analysis. Curr. Protoc. Bioinform. 2016, 55, 14. [CrossRef] [PubMed]

Publisher's Note: MDPI stays neutral with regard to jurisdictional claims in published maps and institutional affiliations.

(C) 2020 by the authors. Licensee MDPI, Basel, Switzerland. This article is an open access article distributed under the terms and conditions of the Creative Commons Attribution (CC BY) license (http://creativecommons.org/licenses/by/4.0/). 